\title{
The Challenging Play of PFO in Cerebrovascular Disease: An Actor that can be an Extra or the Protagonist
}

\author{
Carmelo Buttà ${ }^{1 *}$ and Giuseppe Miceli ${ }^{2}$ \\ ${ }^{1}$ U.O.C. Cardiology, Department of Clinical and Experimental Medicine, Messina (Italy)
}

${ }^{2}$ U.O.C. Internal Medicine with Stroke Care, Department of Health Promotion, Maternal and Child, of Internal and Specialized Medicine of Excellence, Palermo (Italy)

*Corresponding author: Carmelo Buttà, Department of Clinical and Experimental Medicine, University of Messina, Italy

\begin{tabular}{|c|c|}
\hline ARTICLE INFO & ABSTRACT \\
\hline Received: 㗀 July 22, 2019 & Citation: Carmelo Buttà, Giuseppe Miceli. The Challenging Play of PFO in Cerebrovascular \\
\hline Published: 彗 July 26, 2019 & $\begin{array}{l}\text { Disease: An Actor that can be an Extra or the Protagonist. Biomed J Sci \& Tech Res 20(1)- } \\
\text { 2019. BJSTR. MS.ID.003394. }\end{array}$ \\
\hline
\end{tabular}

\section{Mini-Review}

Patent Foramen Ovale (PFO) is an interatrial communication that is considered physiologic during fetal life but in some cases, it can persist even after birth [1]. In the 80s of the last century, it was assumed that PFO could be responsible for a proportion of Cryptogenic Strokes (CS) [2-4] through the mechanism of paradoxical embolism, when a venous thrombus passage to the systemic arterial circulation, via a right-to-left shunt, occurs [5]. Nevertheless, the estimated prevalence of PFO in the general population is around 25\% [6], therefore not all PFOs are responsible for stroke. It was estimated that, exclusively in CS, at least one third of PFOs discovered are likely to be incidental [7]. The closure of an incidental PFO would put patients at risk of procedural and device-related complications while leaving the real cause of stroke unrevealed. In presence of cerebrovascular disease, the real challenge is therefore to understand if an eventual PFO is an extra or the protagonist of disease. As already mentioned, PFO is usually implicated in CS or in the incidental finding of embolism at imaging without known causes [6]. CS is defined as a cerebral infarct not attributed to a recognized source of cardioembolism, large-vessel atherosclerosis, or small-vessel disease, despite extensive cardiac, vascular, hematologic, and serological evaluation [8]. Even if the simultaneous presence of other risk factors does not exclude a causative role of PFO, it is more reasonable consider it the "protagonist" when patients are young and lack other risk factors [6]. In order to establish the causative role of PFO, imaging stroke pattern is not helpful; even if cortical infarcts are commonly embolic, neither the localization nor involvement of grey or white matter are characteristic for PFO [6].

Anatomical factors more related to PFO-associated strokes are an Atrial Septal Aneurysm (ASA), a moderate-to-severe shunt and an atrial septal hypermobility [6]. A Eustachian valve, Chiari network or a long PFO tunnel are also related to PFO-associated strokes, but only in retrospective studies $[9,10]$. Other clinical factors that could increase the probability of a PFO-related embolism are the concomitant presence of deep vein thrombosis (especially if simultaneous with pulmonary embolism) or obstructive sleep apnea, as well as prolonged immobilization or a straining pre-stroke [6]. Further elements associated to a higher recurrence rate of PFO-related embolism are: ASA, PFO diameter, older age, coagulation disorders, higher D-dimer level at admission, and acetylsalicylic acid use rather than oral anticoagulants [6]. Treatment of a PFO should be contemplated in patients affected by stroke or with incidental finding of embolism at imaging, in the absence of a clear alternative etiology, and with anatomical and clinical factors of PFO-linked stroke. In doubtful cases, the RoPE score could be useful as part of a comprehensive individual assessment, but further validation studies are still needed $[6,11]$.

Before defining a stroke as cryptogenic, it is fundamental to exclude aortic or cerebral atherothrombosis or left atrial clot performing transesophageal echocardiography, carotid ultrasonography, computed tomography, or magnetic resonance imaging [12]. 
However, one of the major challenges of CS is the correct recognition of cardioembolic stroke secondary to paroxysmal Atrial Fibrillation (AF), whom may not be identificated by a single 24-hour Holter ECG monitoring. Some studies demonstrated that paroxysmal AF, detected by Insertable Cardiac Monitors (ICM), is very frequent among patients with a recent CS $[13,14]$. Therefore, in patients with negative 24-hour Holter ECG monitoring and without evident causative role of PFO, it is acceptable to consider at least 6 months ICM before conclude on PFO closure or permanent OAC [6]. Since the AF is more frequent among older patients, it is reasonable to consider ICM in patients $<65$ years old if some risk factors for AF are recognized, such as: uncontrolled hypertension or diabetes, structural heart alterations, congestive heart failure, obesity, atrial runs, and pulmonary or thyroid disease [6].

Therapeutic options for the secondary prevention of PFO-related stroke are: PFO closure (with antiplatelet therapy), antiplatelet therapy alone, or anticoagulants [12]. PFO closure is the treatment of choice whenever all therapeutic options are acceptable, especially in comparison with antiplatelet therapy alone [12], as recently showed by CLOSE, RESPECT and REDUCE trials [15-17]. On the other hand, if PFO closure is contraindicated, unacceptable or unavailable, anticoagulants are weakly preferred to antiplatelets since they may decrease ischaemic stroke even if they could probably increase the risk of major bleedings [12]. PFO closure can be rarely burdened by some adverse events: vascular complications, conduction abnormalities, and device dislocation or thrombosis [12]; moreover, it is linked with higher rates of AF $[15,17]$, but the incidence is lowest with the AMPLATZER PFO Occluder [12]. In order to prevent device thrombosis and embolism recurrence, antiplatelet therapy is recommended after PFO closure. There is no agreement regarding exact duration of this therapy. Nevertheless, it is reasonable to prescribe a dual antiplatelet therapy for 1 to 6 months that may be followed by a single antiplatelet therapy for at least 5 years, according to the balance between ischemic and hemorrhagic individual risk of patients [12]. In conclusion, to understand the causative role of PFO in CS represents still today an important challenge for the physician. Nevertheless, it may be defined only after a careful evaluation of clinical, anatomical and imaging characteristics of each individual patient through the critical clinical judgement of an interdisciplinary team.

\section{References}

1. Geva T, Martins JD, Wald RM (2014) Atrial septal defects. Lancet 383: 1921-1932.
2. Lechat P, Mas JL, Lascault G, Loron P, Theard M, et al. (1988) Prevalence of patent foramen ovale in patients with stroke. N Engl J Med 318: 11481152.

3. Handke M, Harloff A, Olschewski M, Hetzel A, Geibel A (2007) Patent foramen ovale and cryptogenic stroke in older patients. N Engl J Med 357: 2262-2268.

4. Webster MW, Chancellor AM, Smith HJ, Swift DL, Sharpe DN, et al. (1988) Patent foramen ovale in young stroke patients. Lancet 2: 11-12.

5. Abdelghani M, El-Shedoudy SA O, Nassif M, Bouma BJ, de Winter RJ (2019) Management of Patients with Patent Foramen Ovale and Cryptogenic Stroke: An Update. Cardiology 15: 1-11.

6. Pristipino C, Sievert H, D’Ascenzo F, Mas JL, Meier B, et al. (2019) European position paper on the management of patients with patent foramen ovale. General approach and left circulation thromboembolism. EuroIntervention 14: 1389-1402.

7. Alsheikh-Ali AA, Thaler DE, Kent DM (2009) Patent foramen ovale in cryptogenic stroke: Incidental or pathogenic? Stroke 40: 2349-2355

8. Yaghi S, Bernstein RA, Passman R, Okin PM, Furie KL (2017) Cryptogenic stroke: Research and practice. Circ Res 120: 527-540.

9. Schuchlenz HW, Saurer G, Weihs W, Rehak P (2004) Persisting eustachian valve in adults: Relation to patent foramen ovale and cerebrovascular events. J Am Soc Echocardiogr 17: 231-233

10. Goel SS, Tuzcu EM, Shishehbor MH, de Oliveira EI, Borek PP, et al. (2009) Morphology of the patent foramen ovale in asymptomatic versus symptomatic (Stroke or Transient Ischemic Attack) patients. Am J Cardiol 103: 124-129.

11. Thaler DE, Di Angelantonio E, Di Tullio MR, Donovan JS, Griffith J, et al. (2013) The Risk of Paradoxical Embolism (RoPE) study: Initial description of the completed database. Int J Stroke 8: 612-619.

12. Kuijpers T, Spencer FA, Siemieniuk RAC, Vandvik PO, Otto CM, et al. (2018) Patent foramen ovale closure, antiplatelet therapy or anticoagulation therapy alone for management of cryptogenic stroke? A clinical practice guideline. BMJ 362: k2515.

13. Sanna T, Diener HC, Passman RS, Di Lazzaro V, Bernstein RA, et al. (2014) Cryptogenic stroke and underlying atrial fibrillation. N Engl J Med 370: 2478-2486.

14. Gladstone DJ, Spring M, Dorian P, Panzov V, Thorpe KE, et al. (2014) Atrial fibrillation in patients with cryptogenic stroke. N Engl J Med 370: 2467-2477.

15. Mas JL, Derumeaux G, Guillon B, Massardier E, Hosseini H, et al. (2017) Patent foramen ovale closure or Anticoagulation vs. Antiplatelets after stroke. N Engl J Med 377: 1011-1021.

16. Saver JL, Carroll JD, Thaler DE, Smalling RW, MacDonald LA, et al. (2017) Long-term outcomes of patent foramen ovale closure or medical therapy after stroke. N Engl J Med 377: 1022-1032.

17. Søndergaard L, Kasner SE, Rhodes JF, Andersen G, Iversen HK, et al. (2017) Patent foramen ovale closure or antiplatelet therapy for cryptogenic stroke. N Engl J Med 377: 1033-1042. 


\section{ISSN: 2574-1241}

DOI: 10.26717/BJSTR.2019.20.003394

Carmelo Buttà. Biomed J Sci \& Tech Res

(c) (i) This work is licensed under Creative

Submission Link: https://biomedres.us/submit-manuscript.php

$\begin{array}{ll}\text { BIOMEDICAL } & \text { Assets of Publishing with us } \\ \text { RESEARCHES } & \text { - Global archiving of articles } \\ \text { - Immediate, unrestricted online access } \\ \text { - Rigorous Peer Review Process }\end{array}$

